\title{
Characterization and potential for reducing optical resonances in Fourier transform infrared spectrometers of the Network for the Detection of Atmospheric Composition Change (NDACC)
}

\author{
Thomas Blumenstock ${ }^{1}$, Frank Hase ${ }^{1}$, Axel Keens ${ }^{2}$, Denis Czurlok ${ }^{2}$, Orfeo Colebatch ${ }^{3}$, Omaira Garcia ${ }^{4}$, \\ David W. T. Griffith ${ }^{5}$, Michel Grutter ${ }^{6}$, James W. Hannigan ${ }^{7}$, Pauli Heikkinen ${ }^{8}$, Pascal Jeseck ${ }^{9}$, Nicholas Jones ${ }^{5}$, \\ Rigel Kivi ${ }^{8}$, Erik Lutsch ${ }^{3}$, Maria Makarova ${ }^{10}$, Hamud K. Imhasin ${ }^{10}$, Johan Mellqvist ${ }^{11}$, Isamu Morino ${ }^{12}$, \\ Tomoo Nagahama ${ }^{13}$, Justus Notholt ${ }^{14}$, Ivan Ortega ${ }^{7}$, Mathias Palm ${ }^{14}$, Uwe Raffalski ${ }^{15}$, Markus Rettinger ${ }^{16}$, \\ John Robinson ${ }^{17}$, Matthias Schneider ${ }^{1}$, Christian Servais ${ }^{18}$, Dan Smale ${ }^{17}$, Wolfgang Stremme ${ }^{6}$, Kimberly Strong ${ }^{3}$, \\ Ralf Sussmann $^{16}$, Yao Té ${ }^{9}$, and Voltaire A. Velazco ${ }^{5}$ \\ ${ }^{1}$ Karlsruhe Institute of Technology (KIT), Institute of Meteorology and Climate Research (IMK-ASF), Karlsruhe, Germany \\ ${ }^{2}$ Bruker Optics GmbH, Ettlingen, Germany \\ ${ }^{3}$ Department of Physics, University of Toronto, Toronto, Canada \\ ${ }^{4}$ Izaña Atmospheric Research Centre (IARC), Meteorological State Agency of Spain (AEMET), Tenerife, Spain \\ ${ }^{5}$ Centre for Atmospheric Chemistry, University of Wollongong, Wollongong, Australia \\ ${ }^{6}$ Centro de Ciencias de la Atmósfera, Universidad Nacional Autónoma de México (UNAM), Mexico City, Mexico \\ ${ }^{7}$ National Center for Atmospheric Research (NCAR), Boulder, CO, USA \\ ${ }^{8}$ Finnish Meteorological Institute (FMI), Sodankylä, Finland \\ ${ }^{9}$ Laboratoire d'Etudes du Rayonnement et de la Matière en Astrophysique et Atmosphères (LERMA-IPSL), Sorbonne \\ Université, CNRS, Observatoire de Paris, PSL Université, Paris, France \\ ${ }^{10}$ Saint Petersburg State University, Atmospheric Physics Department, St. Petersburg, Russia \\ ${ }^{11}$ Department of Earth and Space Science, Chalmers University of Technology, Gothenburg, Sweden \\ ${ }^{12}$ National Institute for Environmental Studies (NIES), Tsukuba, Ibaraki, Japan \\ ${ }^{13}$ Institute for Space-Earth Environmental Research (ISEE), Nagoya University, Nagoya, Japan \\ ${ }^{14}$ Institute of Environmental Physics, University of Bremen, Bremen, Germany \\ ${ }^{15}$ Swedish Institute of Space Physics (IRF), Kiruna, Sweden \\ ${ }^{16}$ Karlsruhe Institute of Technology, IMK-IFU, Garmisch-Partenkirchen, Germany \\ ${ }^{17}$ National Institute of Water and Atmospheric Research Ltd (NIWA), Lauder, New Zealand \\ ${ }^{18}$ Institut d'Astrophysique et de Géophysique, Université de Liège, Liège, Belgium
}

Correspondence: Thomas Blumenstock (thomas.blumenstock@kit.edu)

Received: 7 August 2020 - Discussion started: 4 September 2020

Revised: 3 December 2020 - Accepted: 20 December 2020 - Published: 17 February 2021

\begin{abstract}
Although optical components in Fourier transform infrared (FTIR) spectrometers are preferably wedged, in practice, infrared spectra typically suffer from the effects of optical resonances ("channeling") affecting the retrieval of weakly absorbing gases. This study investigates the level of channeling of each FTIR spectrometer within the Network for the Detection of Atmospheric Composition Change (NDACC). Dedicated spectra were recorded by
\end{abstract}

more than 20 NDACC FTIR spectrometers using a laboratory mid-infrared source and two detectors. In the indium antimonide ( $\mathrm{InSb}$ ) detector domain (1900-5000 $\mathrm{cm}^{-1}$ ), we found that the amplitude of the most pronounced channeling frequency amounts to $0.1 \%$ to $2.0 \%$ of the spectral background level, with a mean of $(0.68 \pm 0.48) \%$ and a median of $0.60 \%$. In the mercury cadmium telluride ( $\mathrm{HgCdTe})$ detector domain (700-1300 $\left.\mathrm{cm}^{-1}\right)$, we find even stronger effects, 
with the largest amplitude ranging from $0.3 \%$ to $21 \%$ with a mean of $(2.45 \pm 4.50) \%$ and a median of $1.2 \%$. For both detectors, the leading channeling frequencies are 0.9 and 0.11 or $0.23 \mathrm{~cm}^{-1}$ in most spectrometers. The observed spectral frequencies of 0.11 and $0.23 \mathrm{~cm}^{-1}$ correspond to the optical thickness of the beam splitter substrate. The $0.9 \mathrm{~cm}^{-1}$ channeling is caused by the air gap in between the beam splitter and compensator plate. Since the air gap is a significant source of channeling and the corresponding amplitude differs strongly between spectrometers, we propose new beam splitters with the wedge of the air gap increased to at least $0.8^{\circ}$. We tested the insertion of spacers in a beam splitter's air gap to demonstrate that increasing the wedge of the air gap decreases the $0.9 \mathrm{~cm}^{-1}$ channeling amplitude significantly. A wedge of the air gap of $0.8^{\circ}$ reduces the channeling amplitude by about $50 \%$, while a wedge of about $2^{\circ}$ removes the $0.9 \mathrm{~cm}^{-1}$ channeling completely. This study shows the potential for reducing channeling in the FTIR spectrometers operated by the NDACC, thereby increasing the quality of recorded spectra across the network.

\section{Introduction}

Ground-based FTIR (Fourier transform infrared) spectroscopy is a widely used technique for measuring total and partial column abundances of a variety of trace gases in the atmosphere. Within the Network for the Detection of Atmospheric Composition Change (NDACC), this technique is used at about 20 sites covering a wide range of geographical latitudes. The NDACC data are used to study shortand long-term variability of the atmosphere as well as for satellite data validation (De Mazière et al., 2018). For both applications, high data quality and station-to-station consistency are of utmost importance. Ground-based FTIR spectroscopy provides data of high quality (e.g., Schneider and Hase, 2008). However, several key instrumental characteristics need to be addressed. These parameters, such as detector non-linearity (Abrams et al., 1994), instrumental line shape (ILS; Hase et al., 1999), intensity fluctuations (KeppelAleks et al., 2007), precise solar tracking (Gisi et al., 2011) and sampling error (Messerschmidt et al., 2010; Dohe et al., 2013), have been studied in some detail and need to be taken into account.

In this paper, channeling - the presence of instrumentinduced periodic oscillations of spectral transmission resulting from internal optical resonances - will be investigated and discussed. In the past, each site or each new spectrometer was tested for channeling individually. This paper describes a network-wide exercise for characterizing channeling in FTIR spectrometers. Channeling is caused by interference of reflections of the incoming light at parallel transmitting surfaces of optical elements. In practice, the resulting channeling amplitudes are less than $10 \%$ in signal. Thus, the retrieved data for species with strong absorption signatures, as, for example, ozone and many others, are less critically affected. However, the retrieved trace gas amounts of weak absorbers can be substantially disturbed. In such cases, channeling becomes an important component of the total error budget.

Recently, time series of column abundances of formaldehyde (HCHO) were retrieved from NDACC FTIR sites (Vigouroux et al., 2018, 2020). The studies of Vigouroux also include an error characterization of the HCHO product. Within the network, two retrieval codes are in use: SFIT4 and PROFFIT. While the retrieval codes were intercompared and show consistent results (Hase et al., 2004), the assumed error budgets differ slightly. The stations using PROFFIT include an error contribution due to channeling while the stations using SFIT4 do not. The result is a larger total error for HCHO data retrieved with PROFFIT as compared to SFIT4 (Vigouroux et al., 2018). In the PROFFIT error calculation, a set of typical channeling frequencies and amplitudes is taken into account. More specifically, channeling amplitudes of $0.5 \%$ ofor four frequencies are assumed: $0.005,0.2,1.0$ and $3.0 \mathrm{~cm}^{-1}$. The resulting error contribution doubles the total error of HCHO column amounts.

In order to make this assumption more robust and to quantify more carefully the differences from spectrometer to spectrometer, an exercise was performed to measure channeling frequencies and amplitudes of NDACC FTIR spectrometers. Since atmospheric spectra are densely populated with absorption signatures interfering with the signal generated by channeling, the test was designed using spectra collected in a laboratory setting. Section 2 briefly describes the origin of channeling, Sect. 3 discusses the setup of this exercise, and Sect. 4 shows the results followed by a discussion. Finally, to reduce the channeling amplitude, the investigation of a modified beam splitter design is presented in Sect. 5, and lastly, Sect. 6 gives the conclusions.

\section{Spectral transmission of a Fabry-Pérot cavity}

In an FTIR spectrometer, the transmitted light passes through several optical components such as optical windows, optical filters and a beam splitter, typically comprised of a beamsplitting layer system deposited on a transparent substrate and a compensator. At the transmitting surfaces of these components, the optical beam is partially reflected. In the case of parallel surfaces, each pair of surfaces defines a cavity (Fig. 1a) in which multiple reflections occur. Due to interference of the reflected light, a standing wave is created (Fig. 1b). This effect is called the Fabry-Pérot or etalon effect or channeling. The optical length of the cavity defines the free spectral range $v_{(\mathrm{FSR})}$ as

$v(\mathrm{FSR})=1 /(2 n d \cos \theta)$ 

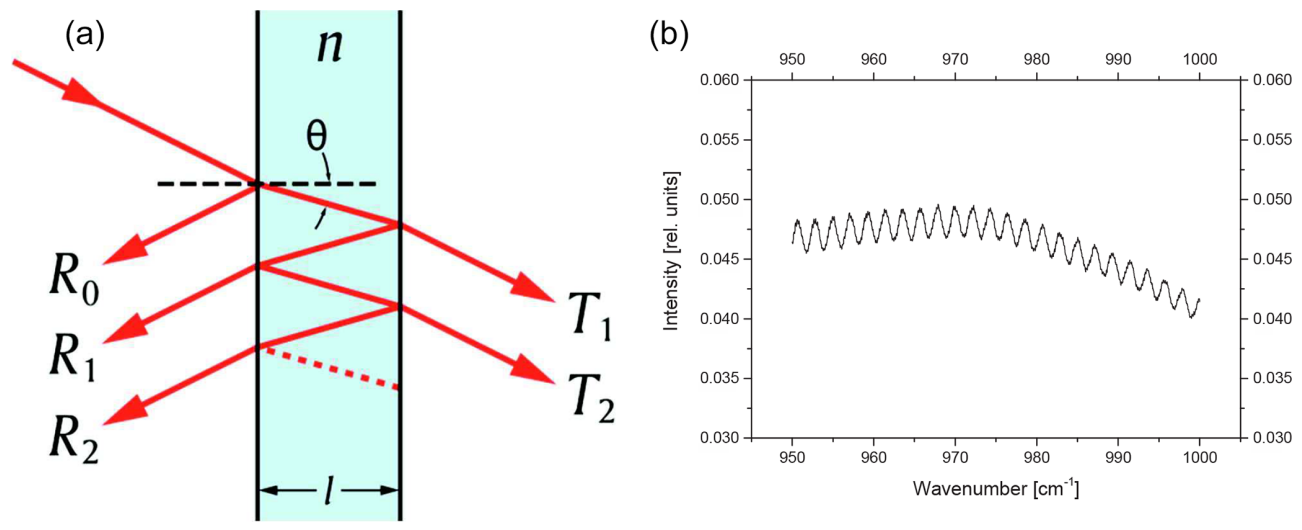

Figure 1. (a) Multiple reflections at parallel surfaces in an optical component where " $l$ " is denoted " $d$ " in Eq. (1) (taken from Wikimedia Commons: https://commons.wikimedia.org, last access: 2 February 2021, Wikipedia.org, 2021). (b) Channeling in an IR spectrum.

Table 1. Free spectral range $v_{(\text {FSR })}$ of some components typically used in NDACC FTIR spectrometers with $\cos \theta=1$.

\begin{tabular}{llrrr}
\hline Material & Used as & $n$ & $d[\mathrm{~mm}]$ & $v_{\text {(FSR) }}\left[\mathrm{cm}^{-1}\right]$ \\
\hline Air & Gap between beam splitter and compensator plate & 1 & 5.5 & 0.91 \\
$\mathrm{KBr}$ & Beam splitter substrate & 1.5 & 15 & 0.22 \\
$\mathrm{CaF}_{2}$ & Beam splitter substrate & 1.4 & 15 & 0.24 \\
$\mathrm{CaF}_{2}$ & Detector window & 1.4 & 1.0 & 3.57 \\
$\mathrm{Ge}$ & Detector window & 4.4 & 1.0 & 1.14 \\
$\mathrm{KRS}-5$ (TlBr-TlI) & Detector window & 2.37 & 1.0 & 2.11 \\
$\mathrm{Sapphire}$ & Detector window & 1.65 & 1.0 & 3.0 \\
$\mathrm{ZnSe}$ & Detector window & 2.2 & 1.0 & 2.27 \\
\hline
\end{tabular}

with $n$ refractive index and $d$ thickness of the optical component (Hecht, 2017). $\theta$ is the angle between incoming light beam and the normal incidence of the optical surface (Fig. 1a). Equation (1) is used to identify the optical element responsible for a certain channeling frequency. Table 1 gives a few examples of $v_{(\mathrm{FSR})}$ for optical materials commonly used in FTIR spectrometers.

The Fabry-Pérot etalons generated by these optical components have rather low reflectivity, and therefore the undesired parasitic effects caused in their spectral transmission are well described as a harmonic oscillation. For demonstrating the plausibility of our empirical experimental results, we here provide some basic considerations concerning the channeling effects created by a Fabry-Pérot etalon of low finesse. Further background information can be found in Ismail et al. (2016) and references herein.

\subsection{Fabry-Pérot effect in a plane-parallel window at normal incidence}

Assume a plane-parallel $\mathrm{KBr}$ window of thickness $d$ at normal incidence. The refractive index of $\mathrm{KBr}$ is 1.5346 at $5 \mu \mathrm{m}$ and 1.5265 at $10 \mu \mathrm{m}$ (see https://refractiveindex.info/?shelf= main\&book=KBr\&page=Li, last access: 2 February 2021, and references therein). We here assume a low finesse, so higher-order contributions to the modulated transmission can be neglected. The channeling results from the superposition of the primary transmitted beam with a parasitic beam which is generated by reflection at the exit surface (as result, traveling in the opposite direction as the primary beam) and afterwards at the entrance surface (as result, being redirected again, traveling again parallel to the primary beam). The ratio of intensities between the parasitic and primary beams is given by the Fresnel relation for normal rays:

$R=\left|\frac{m-1}{m+1}\right|^{2}$

Here, $m$ is the ratio of the refractive indices involved (here, those of $\mathrm{KBr}$ and vacuum or air $n \_$air $=1.00027 \approx 1$ ). Because the parasitic ray undergoes two reflections, the intensity ratio is $1.979 \%$ at $5 \mu \mathrm{m}$ and $1.886 \%$ at $10 \mu \mathrm{m}$. This requires that the ratio of the electric amplitudes of the monochromatic electromagnetic waves represented by the two beams is the square root of these values, so 0.0445 at $5 \mu \mathrm{m}$ and 0.0434 at $10 \mu \mathrm{m}$. From a vector addition of the electric amplitudes of the primary and the parasitic ray the peakto-peak amplitude of the channeling follows: it amounts to a peak-to-peak variation in the intensity of $178 \%$ at $5 \mu \mathrm{m}$ and $174 \%$ at $10 \mu \mathrm{m}$ (note that the channeling signal is detected by measuring variable intensities, not wave amplitudes). 
Table 2. Reflectivities calculated from the Fresnel relations.

\begin{tabular}{lrr}
\hline Wavelength $[\mu \mathrm{m}]$ & $R_{\mathrm{P}}$ & $R_{\mathrm{S}}$ \\
\hline 5 & 0.02845 & 0.06371 \\
10 & 0.02768 & 0.06232 \\
\hline
\end{tabular}

The periodicity of the channeling is determined by the requirement that for constructive interference, the path difference between the primary and the parasitic ray needs to equal the extra optical path length traveled by the parasitic ray:

$2 n d=N \lambda$.

Here, $n$ is the refractive index of the plate, $\lambda$ is the vacuum wavelength, and $N$ is a positive integer number. By rearranging the equation for representation as a function of wavenumbers, we find that the fringe period $\Delta v$ becomes equidistant as a function of wavenumber if the refractive index is constant. If we allow for dispersion $n=n(v)$, the channeling period of Eq. (1) becomes slightly wavenumber dependent.

$\Delta v=\frac{1}{2 n(v) d}$

Note that a resonator formed by a gap instead of $\mathrm{KBr}$ will show no (in vacuum) or much lower (in laboratory air) variability of the fringe period.

\subsection{Fabry-Pérot effect in a plane-parallel $\mathrm{KBr}$ plate at a $30^{\circ}$ angle of incidence}

Now we investigate a plane-parallel $\mathrm{KBr}$ plate of thickness $d$ at a $30^{\circ}$ angle of incidence, the typical angle in the Bruker FTIR systems. The intensities of the primary and parasitic beams now depend on the state of polarization. The Fresnel relations for oblique rays provide the reflectivities for linearly polarized waves with the $\boldsymbol{E}$ vector oscillating in the plane of incidence $\left(R_{\mathrm{P}}\right)$ or perpendicular to it $\left(R_{\mathrm{S}}\right)$ :

$R_{\mathrm{P}}=\left|\frac{\cos \beta-m \cos \alpha}{\cos \beta+m \cos \alpha}\right|^{2}$ and $R_{\mathrm{S}}=\left|\frac{\cos \alpha-m \cos \beta}{\cos \alpha+m \cos \beta}\right|^{2}$.

Here, $\alpha$ is the incidence angle, while $\beta$ is the angle with respect to the normal incidence inside the plate. For a $30^{\circ}$ incidence angle (so $\beta=19.02^{\circ}$ at $5 \mu \mathrm{m}$ and $\beta=19.12^{\circ}$ at $10 \mu \mathrm{m}$ ), we calculate the reflectivities as provided in Table 2 .

While $R_{\mathrm{P}}$ decreased in comparison to the reflectivity for normal incidence $(\approx 0.04)$, the value of $R_{\mathrm{S}}$ increased. Note that under the Brewster angle, $R_{\mathrm{P}}$ would vanish and channeling caused by the beam splitter (BS) could be removed completely. Operation of a BS near the Brewster angle (here $\approx 57^{\circ}$ ) and introduction of a polarizing unit selecting only the perpendicular component for detection would in principle be an alternative approach for removing channeling generated by the BS. However, this would require a complete

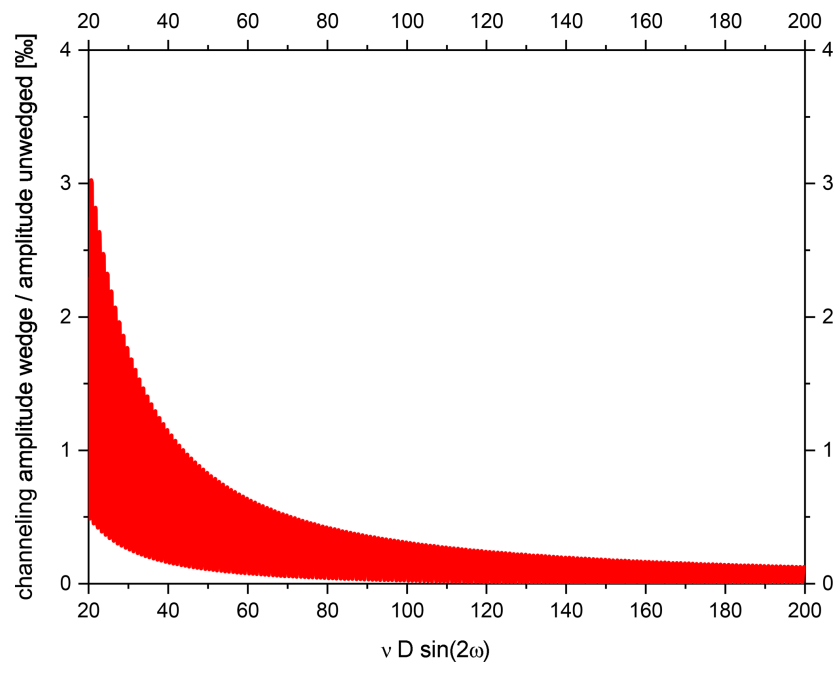

Figure 2. Channeling amplitude as a function of wedge angle.

redesign of the spectrometer setup (using the BS at a rather inconvenient angle of incidence of nearly $60^{\circ}$ ) and it would reduce the amount of signal if the source provides unpolarized radiation. (However, the significant polarization dependency of the channeling following from the Fresnel equations could be used to prove whether a channeling fringe is created by the BS by using a polarization filter in front of the detector.) Here, if we work with an unpolarized source, we can assume that the channeling amplitude will not be very different from the amplitude estimated for normal incidence.

The period of the channeling fringe as a function of wavenumber becomes shorter for geometric reasons when the plate orientation is tilted away from normal incidence: the effective thickness of the BS increases. Note that the change of the channeling period in the presence of dispersion is now created by two mechanisms: the changing relation between optical and geometric path length and the changing angle of transmission:

$\Delta v=\frac{\cos \beta}{2 n(v) d}$.

\subsection{Fabry-Pérot effect in a wedged plate}

We have seen that there is no significant impact of wavenumber on the channeling amplitude for a plane-parallel plate. We will, however, show that a wedge of certain amount is significantly more effective in suppressing channeling at shorter wavelengths.

For our investigation, we assume that the source is incoherent. Therefore, the primary beam can only interfere with the parasitic beam deviated by the wedge (not with a parasitic beam emerging from a different position in the source and exiting the BS under the same angle as the primary beam). As result of the wedge, the wave front of the parasitic beam is now tilted with respect to the primary beam. We analyze the 
resulting effect on the circular aperture of the collimator focusing the radiation emerging from the interferometer on the exit aperture. The tilt between the outgoing wave fronts of the primary and parasitic plane waves generates equidistant straight stripes of constant phase shift in that plane (stripe orientation perpendicular to wedge). What has been a uniform variation of brightness across the collimator aperture (when either tuning wavelength or plate thickness) now becomes a shift of the stripe pattern perpendicular to the orientation of the stripes. We can estimate the damping effect introduced by the wedge by determining the residual brightness fluctuations emerging from the shifting stripe pattern (technically by integration over the aperture). Obviously, if the stripe pattern becomes denser (larger wedge or shorter wavelength), the brightness fluctuations are further and further reduced. Figure 2 shows the amplitude of the integrated brightness fluctuation as a function of cycles across the aperture of the collimator (each cycle is equivalent to adding a detuning of one wavelength across the aperture of the collimator), given by

$n_{\text {cycles }}=v D \sin (2 \omega)$.

Here, $v$ is the wavenumber, $D$ the beam diameter and $\omega$ the wedge angle.

Note that our consideration shows that the channeling amplitude is reduced when (1) the aperture of the collimator (or, equivalently, the beam diameter supported by the interferometer) is increased, (2) the wavelength is reduced, or (3) the wedge angle is increased.

While a Fabry-Pérot spectrometer is designed and aligned such that the surfaces are parallel to build a cavity, an FTIR spectrometer is designed differently: in order to reduce or avoid channeling, optical components need to be wedged or installed with a large tilt. A large tilt is not feasible in many cases. Thus, optical components are normally wedged. As shown in this section, wedged optical components reduce channeling because the reflected beams do not superimpose and thus do not interfere with each other. These wedged components require a special design and limit compatibility with non-wedged devices. Furthermore, some components such as detector elements are not available as wedged versions (the partially transparent detector element can also act as an optical cavity). Therefore, in practice, it is challenging to build an FTIR spectrometer that is completely free of channeling.

\section{Channeling test exercise}

\subsection{Experimental setup}

In atmospheric spectra, channeling can be difficult to see due to the presence of complex atmospheric signatures. Therefore, laboratory spectra are used for this exercise, recorded either with a mid-infrared globar or with a black body of at least $1000^{\circ} \mathrm{C}$ temperature. Since these types of sources do (a)

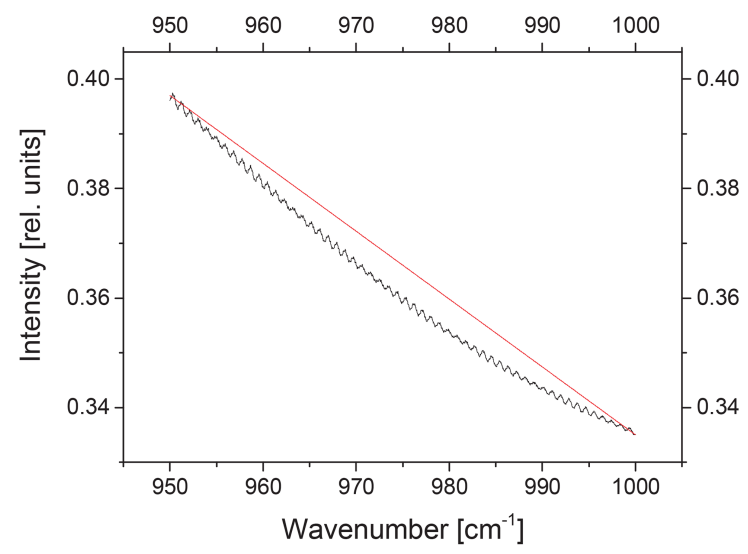

(b)

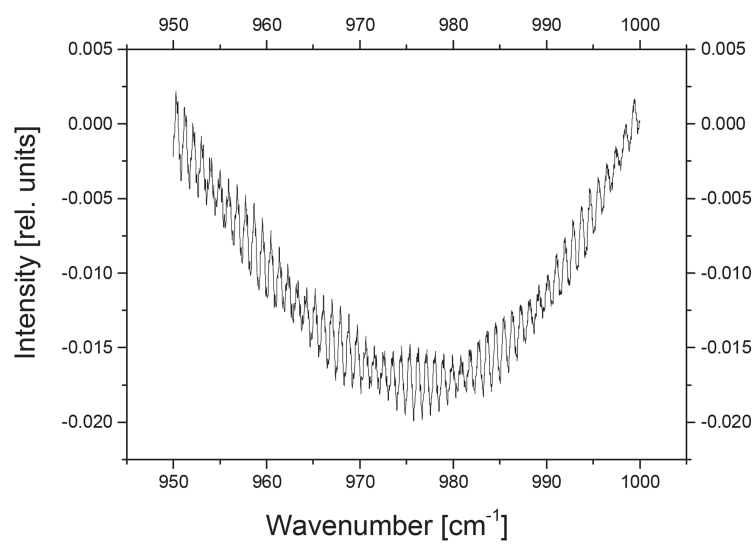

(c)

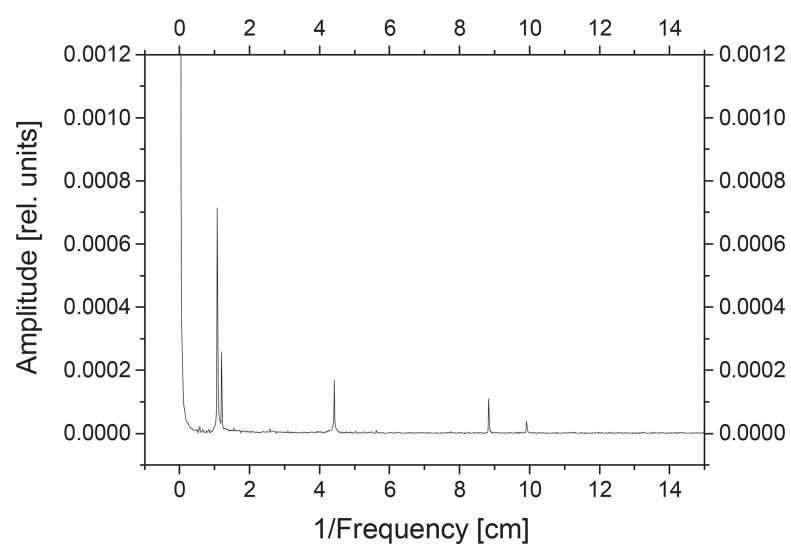

Figure 3. Analysis of a channeling test spectrum: (a) cut off a window of $50 \mathrm{~cm}^{-1}$; a straight line is calculated that connects the ends of the spectrum (red line); (b) normalize background by dividing this straight line and subtract a constant of 1; (c) result of FFT analysis. 
Table 3. List of spectrometers contributing to the channeling test exercise, sorted by latitude of the site, from north (Eureka) to south (Arrival Heights).

\begin{tabular}{|c|c|c|c|c|c|}
\hline Site & Acronym & Type & Beam splitter setup & Optical filter & Team \\
\hline Eureka & EUR & Bruker $125 \mathrm{HR}$ & $\mathrm{KBr}$ & no. $3 \&$ no. 6 & U Toronto \\
\hline Ny-Ålesund & NY & Bruker 120/5 HR & $\mathrm{KBr}$ for $\mathrm{HgCdTe}, \mathrm{CaF}_{2}$ for $\mathrm{InSb}$ det. & no. $3 \&$ no. 6 & U Bremen \\
\hline Thule & THU & Bruker $125 \mathrm{HR}$ & $\mathrm{KBr}$ & no. 3 & NCAR \\
\hline Kiruna & KIR & Bruker 120/5 HR & $\mathrm{KBr}$ & no. $3 \&$ no. 6 & KIT-ASF, IRF \\
\hline Sodankylä & SOD & Bruker $125 \mathrm{HR}$ & $\mathrm{CaF}_{2}$, no $\mathrm{HgCdTe}$ det. & no. 3 & FMI \\
\hline Harestua & HAR & Bruker $120 \mathrm{M}$ & $\mathrm{KBr}$ & no. $3 \&$ no. 8 & U Gothenburg \\
\hline St. Petersburg & STP & Bruker $120 \mathrm{HR}$ & $\mathrm{KBr}$ & ind. no. $3 \&$ no. 6 & $\mathrm{SPbU}$ \\
\hline Bremen & BRE & Bruker $125 \mathrm{HR}$ & $\mathrm{KBr}$ & no. $3 \&$ no. 6 & U Bremen \\
\hline Karlsruhe & KAR & Bruker $125 \mathrm{HR}$ & $\mathrm{CaF}_{2}$, no $\mathrm{HgCdTe}$ det. & no. 3 & KIT-ASF \\
\hline Paris & PAR & Bruker $125 \mathrm{HR}$ & $\mathrm{KBr}$ for $\mathrm{HgCdTe}, \mathrm{CaF}_{2}$ for $\mathrm{InSb}$ det. & ind. no. $3 \&$ no. 7 & Sorbonne U \\
\hline Garmisch & GAR & Bruker $125 \mathrm{HR}$ & $\mathrm{CaF}_{2}$, no $\mathrm{HgCdTe}$ det. & no. 3 & KIT-IFU \\
\hline Zugspitze & ZUG & Bruker 120/5 HR & $\mathrm{KBr}$ & no. $3 \&$ no. 6 & KIT-IFU \\
\hline Jungfraujoch & JJO & Bruker $120 \mathrm{HR}$ & $\mathrm{KBr}$ & no. $3 \&$ no. 6 & U Liège \\
\hline Toronto & TOR & BOMEM DA8 & $\mathrm{KBr}$ & no. $3 \&$ no. 6 & U Toronto \\
\hline Rikubetsu & RIK & Bruker 120/5 HR & $\mathrm{KBr}$ for $\mathrm{HgCdTe}, \mathrm{CaF}_{2}$ for $\mathrm{InSb}$ det. & no. $3 \&$ no. 6 & U Nagoya, NIES \\
\hline Boulder & BOU & Bruker 120/5 HR & $\mathrm{KBr}$ & no. 3 & NCAR \\
\hline Tsukuba & TSU & Bruker $125 \mathrm{HR}$ & $\mathrm{KBr}$ for $\mathrm{HgCdTe}, \mathrm{CaF}_{2}$ for $\mathrm{InSb}$ det. & no. $3 \&$ no. 6 & NIES \\
\hline Izaña & IZ & Bruker 120/5 HR & $\mathrm{KBr}$ & no. $3 \&$ no. 6 & AEMet, KIT-ASF \\
\hline Mauna Loa & MLO & Bruker 120/5 HR & $\mathrm{KBr}$ & no. $3 \&$ no. 6 & NCAR \\
\hline Altzomoni & ALT & Bruker 120/5 HR & $\mathrm{KBr}$ & no. $3 \&$ no. 6 & UNAM \\
\hline Wollongong & WOL & Bruker $125 \mathrm{HR}$ & $\mathrm{KBr}$ & no. $3 \&$ no. 7 & U Wollongong \\
\hline Lauder & LAU & Bruker $120 \mathrm{HR}$; Bruker $125 \mathrm{HR}$ & $\mathrm{KBr} ; \mathrm{KBr}$ & no. $3 \&$ no. 7 ; no. $3 \&$ no. 6 & NIWA \\
\hline Arrival Heights & $\mathrm{AH}$ & Bruker $125 \mathrm{HR}$ & $\mathrm{KBr}$ & no. $3 \&$ no. 6 & NIWA \\
\hline
\end{tabular}

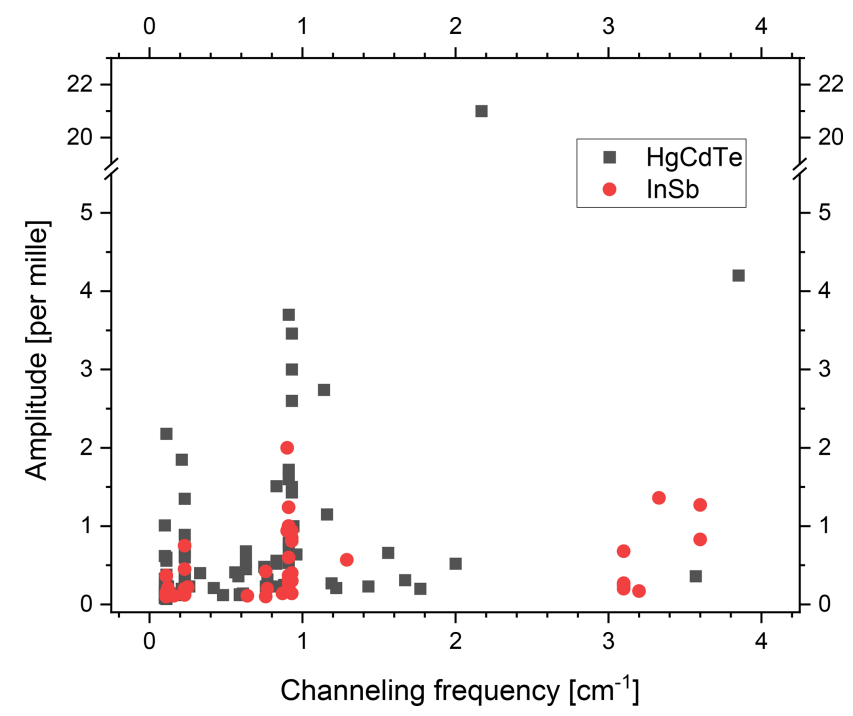

Figure 4. Amplitude of channeling frequencies as observed in InSb and $\mathrm{HgCdTe}$ test spectra.

not include a window, no additional channeling is added to the spectra. A temperature of $1000{ }^{\circ} \mathrm{C}$ is required to record spectra with a sufficient signal-to-noise ratio in a reasonable amount of time.

Within NDACC, two detectors and the NDACC filter set are used (Table A1). The optical filters are used to increase the signal-to-noise ratio of the spectra. The NDACC filters have a wedge of $0.17^{\circ}$ and therefore, if properly oriented, do not cause channeling. Therefore, not all filters but both detectors were included in this exercise. More specifically, NDACC filter no. 3 (2400 to $3000 \mathrm{~cm}^{-1}$ spectral range) for the indium antimonide (InSb) detector and NDACC filter no. 6 (700 to $1300 \mathrm{~cm}^{-1}$ spectral range) for the mercury cadmium telluride $(\mathrm{HgCdTe})$ detector were used. Some sites (Harestua, Paris, Wollongong and Lauder 120 HR) use filter no. 7 (700 to $1000 \mathrm{~cm}^{-1}$ spectral range) and no. 8 (1000 to $1400 \mathrm{~cm}^{-1}$ spectral range) instead of filter no. 6 (Table 3). In this case, filter no. 7 was used for this exercise. Filter no. 3 was selected since this filter range is used for the retrieval of HCHO column abundances.

Multiple reflections within optical components such as optical windows or beam splitters typically show channeling frequencies of a few tenths of a wavenumber up to a few wavenumbers. In general, higher-frequency channeling with wavenumbers below $0.1 \mathrm{~cm}^{-1}$ might occur when different optical components form the surfaces of the resulting cavity; e.g., in the Bruker $120 \mathrm{HR}$ spectrometer, the rim of the entrance field stop is part of a resonator of about $1 \mathrm{~m}$ length. However, this is seldom the case in an FTIR spectrometer and, due to the high frequency, easily detectable even in atmospheric spectra.

In order to focus on channeling due to multiple reflections inside optical components and to achieve a very good signalto-noise ratio, a spectral resolution of $0.05 \mathrm{~cm}^{-1}$ (optical path difference of $180 \mathrm{~cm}$ ) was chosen. This resolution allowed us to add a thousand interferograms within a few hours, thereby achieving a signal-to-noise ratio that allowed channeling amplitudes to be detected and quantified on a per mille scale. 
Table 4. Leading channeling frequencies (F) and their amplitudes (A) in the InSb detector regime. Channeling amplitudes larger than $0.6 \%$ o are printed in bold.

\begin{tabular}{|c|c|c|c|c|c|c|c|c|}
\hline FTIR site & $\mathrm{F} 1\left[\mathrm{~cm}^{-1}\right]$ & A $1[\% o]$ & $\mathrm{F} 2\left[\mathrm{~cm}^{-1}\right]$ & A $2[\% o]$ & $\mathrm{F} 3\left[\mathrm{~cm}^{-1}\right]$ & A $3[\% o]$ & $\mathrm{F} 4\left[\mathrm{~cm}^{-1}\right]$ & A $4[\% o]$ \\
\hline Eureka & 0.93 & 0.14 & 0.23 & 0.05 & 0.11 & 0.004 & & \\
\hline Ny-Ålesund & 0.90 & 2.0 & 0.11 & 0.08 & & & & \\
\hline Thule & 0.91 & 1.0 & 0.23 & 0.18 & 0.11 & 0.15 & 3.1 & 0.27 \\
\hline Kiruna & 0.85 & 0.05 & 0.11 & 0.003 & 0.76 & 0.1 & & \\
\hline Sodankylä & 0.93 & 0.3 & 0.12 & 0.03 & 0.11 & 0.024 & 0.25 & 0.01 \\
\hline Harestua & 0.91 & 0.37 & 0.10 & 0.02 & 3.33 & 1.36 & & \\
\hline St. Petersburg & 0.93 & 0.3 & 0.23 & 0.12 & 0.16 & 0.11 & 0.77 & 0.20 \\
\hline Bremen & 0.93 & 0.3 & 0.23 & 0.16 & 0.11 & 0.05 & & \\
\hline Karlsruhe & 0.87 & 0.14 & & & 1.29 & 0.57 & & \\
\hline Paris & 0.91 & 0.2 & 0.25 & 0.05 & & & & \\
\hline Garmisch & 0.91 & 0.6 & 0.10 & $<0.1$ & 3.1 & 0.24 & & \\
\hline Zugspitze & 0.91 & 0.26 & 0.11 & 0.025 & 0.10 & 0.035 & & \\
\hline Jungfraujoch & 0.91 & 1.24 & 0.23 & 0.08 & 0.12 & 0.02 & & \\
\hline Toronto & 3.10 & 0.68 & 0.21 & 0.05 & 0.11 & 0.02 & & \\
\hline Rikubetsu & 0.90 & 0.94 & 0.25 & 0.22 & 0.11 & 0.11 & 3.2 & 0.17 \\
\hline Boulder & 0.93 & 0.81 & 0.23 & 0.75 & 0.11 & 0.11 & 3.6 & 0.83 \\
\hline Tsukuba & 0.93 & 0.94 & 0.12 & 0.21 & 0.11 & 0.10 & & \\
\hline Izaña - 2018 & 0.76 & 0.42 & 0.10 & 0.09 & 0.11 & 0.06 & 3.6 & 1.27 \\
\hline Izaña - 2019 & 0.83 & 0.07 & 0.10 & 0.02 & 0.11 & 0.03 & 3.1 & 0.20 \\
\hline Mauna Loa & 0.93 & 0.85 & 0.23 & 0.45 & 0.11 & 0.36 & & \\
\hline Altzomoni & 0.64 & 0.11 & 1.82 & 0.04 & 0.74 & 0.03 & & \\
\hline Wollongong & 0.93 & 0.40 & 0.23 & 0.20 & 0.11 & 0.03 & & \\
\hline Lauder $120 \mathrm{HR}$ & 0.91 & 0.32 & 0.23 & 0.08 & 0.11 & 0.02 & & \\
\hline Lauder 125 HR & 0.91 & 1.0 & 0.23 & 0.14 & 0.11 & 0.37 & 0.10 & 0.06 \\
\hline Arrival Heights & 0.91 & 0.94 & 0.23 & 0.03 & 0.12 & 0.11 & 0.10 & 0.09 \\
\hline
\end{tabular}

\subsection{Analysis of channeling test spectra}

To quantify channeling frequencies and their amplitudes, an FFT (fast Fourier transform) analysis of the spectra was conducted. First of all, a spectral interval was chosen with a nearly constant intensity: 950 to $1000 \mathrm{~cm}^{-1}$ for $\mathrm{HgCdTe}$ and 2550 to $2600 \mathrm{~cm}^{-1}$ for InSb spectra. This step was carried out using OPUS ${ }^{\mathrm{TM}}$, a software package from Bruker Optics to control FTIR spectrometers (Fig. 3a). Then, the background was normalized by dividing a straight line that connects the ends of the spectrum using Origin ${ }^{\mathrm{TM}}$ software (red line in Fig. 3a). The quotient minus 1 is the basis for the FFT analysis (Fig. 3b). Finally, an inverse FFT was conducted also with Origin ${ }^{\mathrm{TM}}$ software (Fig. 3c).

\section{Results and discussion}

In this section, the results are presented for more than 20 spectrometers. Table 3 provides the list of spectrometers included in this study. Please note that a few spectrometers do not include an $\mathrm{HgCdTe}$ detector: Garmisch, Karlsruhe and Sodankylä.

These sites primarily serve the TCCON (Total Carbon Column Observing Network; Wunch et al., 2010) and just contribute with InSb spectra to NDACC and to this exercise.
These spectrometers use a $\mathrm{CaF}_{2}$ beam splitter instead of $\mathrm{KBr}$; the latter is normally used in NDACC for enabling measurements in the $\mathrm{HgCdTe}$ spectral range. The Ny-Ålesund, Paris, Rikubetsu and Tsukuba sites use a $\mathrm{CaF}_{2}$ beam splitter for $\mathrm{InSb}$ and a $\mathrm{KBr}$ beam splitter for $\mathrm{HgCdTe}$ measurements. Tables 4 and 5 list the detected channeling frequencies and their amplitudes in spectra recorded with $\mathrm{InSb}$ and $\mathrm{HgCdTe}$ detectors, respectively.

\subsection{InSb detector domain}

Figure 4 shows the detected channeling frequencies and their amplitudes in InSb spectra analyzed at about $2600 \mathrm{~cm}^{-1}$. Most spectrometers show the expected channeling frequencies: about 0.9 and 0.11 or $0.23 \mathrm{~cm}^{-1}$. These frequencies are consistent with (i) the gap between the beam splitter and compensator plate $\left(0.9 \mathrm{~cm}^{-1}\right)$, and (ii) the beam splitter substrate $\left(0.23 \mathrm{~cm}^{-1}\right.$; Table 1$)$. A frequency of $0.11 \mathrm{~cm}^{-1}$ corresponds to a resonator due to both substrates, the beam splitter and the compensator plate.

A few spectrometers (Harestua, Garmisch, Toronto, Boulder and Izaña - 2018) show an additional channeling fringe with a frequency of about $3 \mathrm{~cm}^{-1}$. This is due to the detector window that is often made of sapphire or calcium fluoride $\left(\mathrm{CaF}_{2}\right)$. Also in Izaña, this channeling frequency was 
Table 5. Leading channeling frequencies (F) and their amplitudes (A) in the HgCdTe detector regime. Channeling amplitudes larger than $1.2 \%$ are printed in bold.

\begin{tabular}{|c|c|c|c|c|c|c|c|c|}
\hline FTIR site & $\mathrm{F} 1\left[\mathrm{~cm}^{-}\right]$ & A $1[\% o]$ & $\mathrm{F} 2\left[\mathrm{~cm}^{-1}\right]$ & A $2[\% o]$ & $\mathrm{F} 3\left[\mathrm{~cm}^{-1}\right]$ & A $3[\% o]$ & $\mathrm{F} 4\left[\mathrm{~cm}^{-1}\right]$ & A $4[\% o]$ \\
\hline \multirow[t]{2}{*}{ Eureka } & 0.93 & 1.5 & 0.23 & 0.2 & 0.11 & 0.14 & & \\
\hline & & & & & 0.10 & 0.05 & & \\
\hline \multirow[t]{2}{*}{ Ny-Ålesund } & 0.91 & 1.6 & 0.23 & 0.89 & 0.11 & 0.60 & 2.17 & 21 \\
\hline & & & 0.21 & 1.85 & 0.10 & 0.62 & & \\
\hline Kiruna & 0.77 & 0.32 & 0.59 & 0.12 & 0.11 & 0.07 & & \\
\hline \multirow[t]{2}{*}{ Harestua } & 0.91 & 3.7 & 0.23 & 0.73 & 1.56 & 0.66 & 3.85 & 4.2 \\
\hline & & & 0.11 & 0.16 & 0.58 & 0.36 & & \\
\hline \multirow[t]{2}{*}{ St. Petersburg } & 0.94 & 1.0 & 0.23 & 0.30 & 2.0 & 0.52 & & \\
\hline & & & 0.33 & 0.40 & 1.77 & 0.20 & & \\
\hline \multirow{2}{*}{ Bremen } & 0.93 & 1.43 & 0.23 & 0.34 & 0.11 & 0.22 & & \\
\hline & 0.83 & 0.52 & & & 0.10 & 0.08 & & \\
\hline \multirow[t]{2}{*}{ Paris } & 0.83 & 0.56 & 0.26 & 0.23 & 0.21 & 0.13 & & \\
\hline & & & 0.23 & 0.37 & 0.12 & 0.23 & & \\
\hline \multirow[t]{2}{*}{ Zugspitze } & 0.91 & 0.79 & 0.23 & 0.25 & 0.11 & 0.18 & 3.57 & 0.36 \\
\hline & & & & & 0.10 & 0.19 & & \\
\hline \multirow[t]{2}{*}{ Jungfraujoch } & 0.91 & 0.53 & 0.23 & 0.60 & 0.11 & 0.17 & & \\
\hline & & & 0.21 & 0.12 & 0.10 & 0.06 & & \\
\hline \multirow[t]{2}{*}{ Toronto } & 0.96 & 0.64 & 0.21 & 0.20 & 0.10 & 0.10 & & \\
\hline & 0.48 & 0.12 & & & & & & \\
\hline \multirow[t]{2}{*}{ Rikubetsu } & 0.93 & 1.44 & 0.23 & 0.62 & 0.11 & 2.18 & 0.42 & 0.21 \\
\hline & 0.83 & 1.51 & 0.18 & 0.14 & 0.10 & 1.01 & & \\
\hline \multirow[t]{2}{*}{ Tsukuba } & 0.93 & 3.46 & 0.23 & 0.67 & 0.11 & 0.38 & 1.19 & 0.27 \\
\hline & & & & & 0.10 & 0.33 & & \\
\hline \multirow[t]{2}{*}{ Izaña - 2018} & 0.76 & 0.23 & 0.63 & 0.45 & 0.11 & 0.13 & & \\
\hline & & & 0.56 & 0.41 & 0.10 & 0.13 & & \\
\hline Izaña - 2019 & 0.75 & 0.48 & 0.63 & 0.54 & 0.11 & 0.17 & & \\
\hline \multirow{2}{*}{ Mauna Loa } & 0.93 & 2.60 & 0.23 & 1.35 & 0.11 & 0.56 & 0.61 & 0.14 \\
\hline & & & & & 0.10 & 0.10 & & \\
\hline \multirow[t]{2}{*}{ Altzomoni } & 0.88 & 0.25 & 1.67 & 0.31 & 0.11 & 0.08 & 1.22 & 0.21 \\
\hline & 0.63 & 0.68 & 1.43 & 0.23 & & & & \\
\hline \multirow[t]{2}{*}{ Wollongong } & 0.93 & 3.00 & 0.23 & 0.25 & 0.11 & 0.16 & & \\
\hline & 0.82 & 0.23 & 0.59 & 0.13 & & & & \\
\hline \multirow[t]{2}{*}{ Lauder $120 \mathrm{HR}$} & 0.91 & 0.72 & 0.23 & 0.06 & 0.11 & 0.12 & 1.51 & 0.08 \\
\hline & & & & & 0.10 & 0.07 & & \\
\hline \multirow[t]{2}{*}{ Lauder $125 \mathrm{HR}$} & 0.91 & 1.69 & 0.23 & 0.41 & 0.11 & 0.23 & 1.14 & 2.74 \\
\hline & & & & & 0.10 & 0.11 & & \\
\hline \multirow[t]{2}{*}{ Arrival Heights } & 0.91 & 1.72 & 0.23 & 0.18 & 0.11 & 0.12 & 1.16 & 1.15 \\
\hline & & & & & 0.10 & 0.17 & & \\
\hline
\end{tabular}




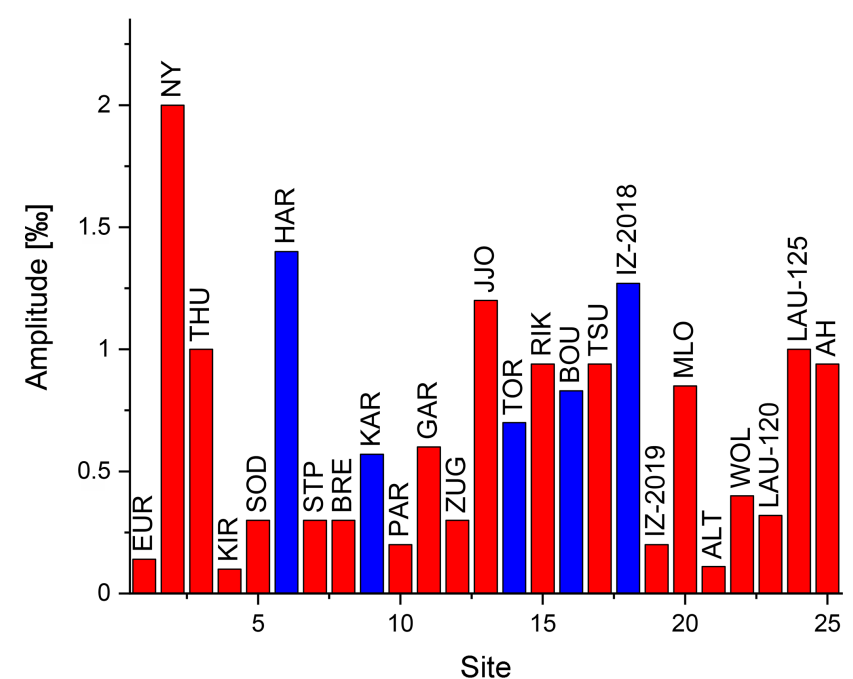

Figure 5. Amplitude of the largest channeling fringe in the test spectrum using an InSb detector and NDACC filter no. 3. Red bars indicate channeling due to the beam splitter air gap and blue bars indicate the detector window as a source of channeling.

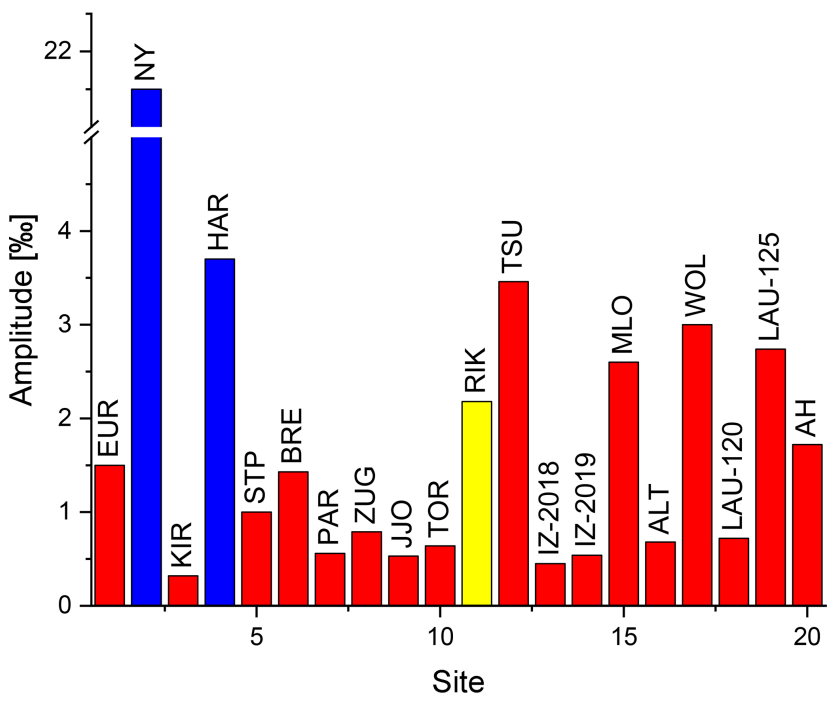

Figure 6. Amplitude of the largest channeling fringe in the $\mathrm{HgCdTe}$ test spectrum. Red bars indicate channeling due to the beam splitter air gap, the yellow bar indicates beam splitter substrate, and blue bars indicate the detector window as a source of channeling.

detected in 2018. In December 2018, the detector was exchanged because of decreasing sensitivity. The new detector (Izaña - 2019) shows much lower channeling. Detectors purchased in the 1990s sometimes had a detector window with insufficient wedge.

Figure 5 shows the amplitude of the strongest channeling frequency of each spectrometer. The amplitudes range from $0.1 \%$ to $2.0 \%$ with a mean of $(0.68 \pm 0.48) \%$ and a median of $0.60 \%$. In most cases, the channeling caused by the gap of the beam splitter is the most pronounced one. These mean

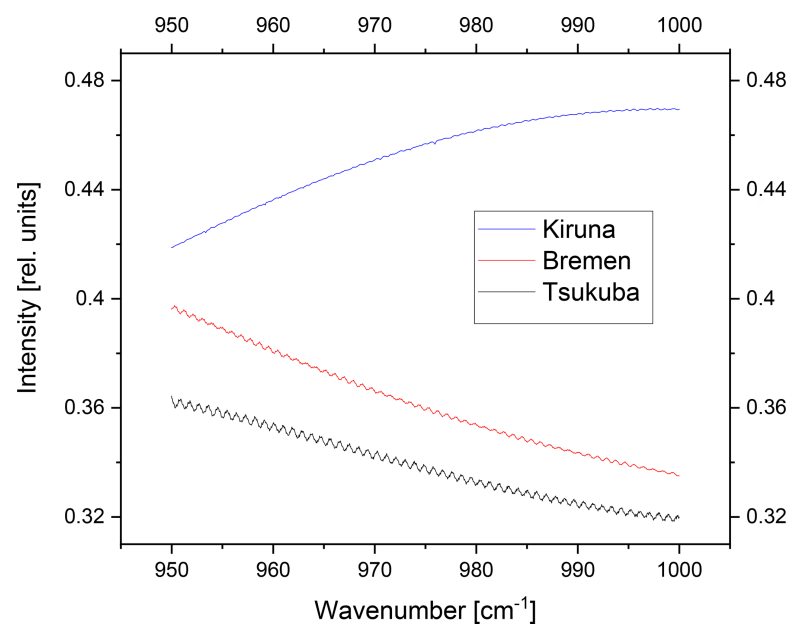

Figure 7. $\mathrm{HgCdTe}$ spectra with low $(0.32 \%$ ), medium $(1.43 \%$ ) and high $\left(3.46 \%\right.$ ) channeling amplitude at $0.9 \mathrm{~cm}^{-1}$ frequency.

and median are consistent with the PROFFIT error estimate of $0.5 \%$ as used in Vigouroux et al. (2018). However, the channeling amplitude differs strongly from spectrometer to spectrometer, and a few spectrometers show an amplitude of up to $21 \%$.

\subsection{HgCdTe detector domain}

Figure 4 and Table 5 present major channeling frequencies and their amplitudes in spectra recorded with an $\mathrm{HgCdTe}$ detector at about $1000 \mathrm{~cm}^{-1}$. As for the InSb detector, most spectrometers show two dominant channeling frequencies: about 0.9 and 0.1 or $0.2 \mathrm{~cm}^{-1}$ caused by the beam splitter (Table 1). Two spectrometers (Ny-Ålesund and Harestua) show an additional channeling frequency of 2.17 and $3.85 \mathrm{~cm}^{-1}$, indicating that the wedge of the detector window is not sufficient in these cases.

Figure 6 shows the amplitude of the strongest channeling frequency of each spectrometer. The amplitudes range from $0.3 \%$ to $21 \%$ with a mean of $(2.45 \pm 4.50) \%$ and a median of $1.2 \%$. In most cases, channeling caused by the gap of the beam splitter is the most pronounced one. The amplitude is even larger compared to the InSb domain, which confirms that the wedge is more efficient in reducing the channeling at shorter wavelengths, as calculated in Sect. 2. At several sites, a reduction of channeling amplitudes would be desirable in order to improve trace gas retrievals of species with weak signatures, in particular from $\mathrm{HgCdTe}$ spectra, e.g., of $\mathrm{ClONO}_{2}, \mathrm{HNO}_{3}$ or $\mathrm{SF}_{6}$.

As for the InSb domain, channeling amplitudes differ strongly from spectrometer to spectrometer. Figure 7 shows $\mathrm{HgCdTe}$ spectra with different levels of channeling of the same frequency (about $0.9 \mathrm{~cm}^{-1}$ ), demonstrating the need for increasing the wedge of the gap and narrowing the tolerances of wedges in the manufacturing of the beam splitters. 

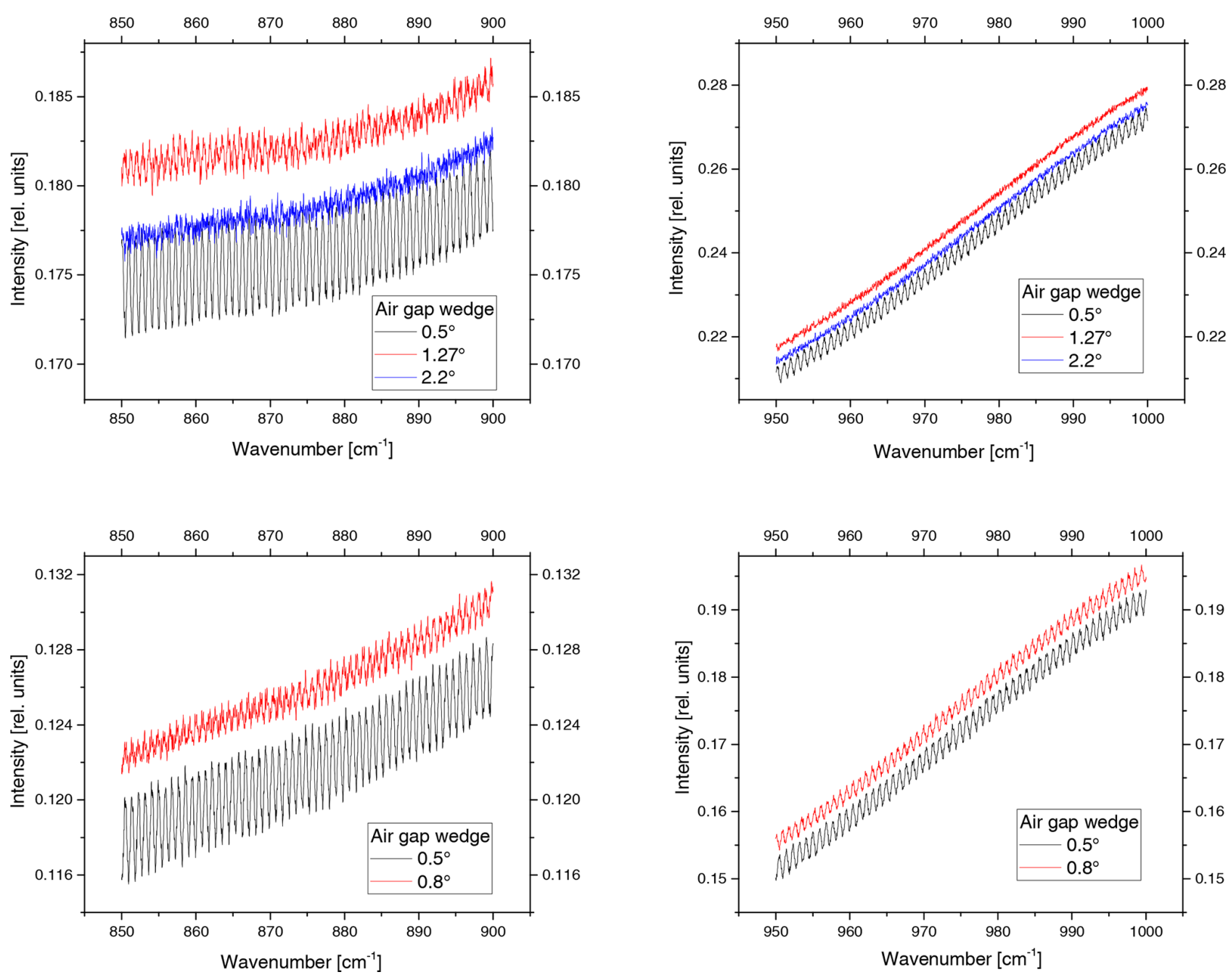

Figure 8. HgCdTe spectra recorded with different wedges of the air gap in between beam splitter and compensator plate for the 850 to $950 \mathrm{~cm}^{-1}$ and the 950 to $1000 \mathrm{~cm}^{-1}$ spectral ranges. These measurements were made at Bruker Corporation in Ettlingen using the same instrument.

\section{Investigation of a modified beam splitter design for reducing channeling}

This test exercise has found that the channeling amplitude differs strongly from spectrometer to spectrometer. A few spectrometers (at Altzomoni, Izaña, Karlsruhe and Kiruna) use customer-specific beam splitters with an increased wedge of $1.75^{\circ}$ for the air gap and $0.17^{\circ}$ for the $\mathrm{CaF}_{2}$ substrate and $0.13^{\circ}$ for the $\mathrm{KBr}$ substrate. Their channeling amplitudes are the lowest among all the spectrometers studied in this paper. Unfortunately, this type of beam splitter is not a standard device and is not compatible with standard beam splitters, as it requires a realignment of the interferometer. Namely due to its incompatibility with unwedged far-infrared pellicle beam splitters, the manufacturer Bruker adheres to the standard design with lower substrate wedge.

To avoid the need for strongly wedged substrates, a different approach is proposed here. We focus on the wedge of the gap between the beam splitter and the compensator plate. Since the largest channeling amplitude (at $0.9 \mathrm{~cm}^{-1}$ frequency) is caused by the air gap, an increased wedge of this gap has the potential to reduce channeling significantly. The typical air gap wedge for the Bruker beam splitter is $0.5^{\circ}$. Different spacers with wedges of $0.5,1.27$ and $2.2^{\circ}$ have been manufactured by Bruker and tested. Figure 8 (upper panels) shows the resulting channeling test spectra recorded with an $\mathrm{HgCdTe}$ detector. Similar to most of the NDACC spectrometers, the spectrum of the $0.5^{\circ}$ wedged beam splitter shows a pronounced channeling with an amplitude of $5.7 \%$. In contrast, the 1.27 and $2.2^{\circ}$ wedged beam splitters are (nearly) free of channeling, with an amplitude of 0.46 and of $0.87 \%$, respectively, which is close to the noise level of these spectra. Analyzed in the 850 to $900 \mathrm{~cm}^{-1}$ spectral range, the amplitude is $8.9 \%, 3.3 \%$ and $0.6 \%$ for a wedge of $0.5,1.27$ and $2.2^{\circ}$, respectively. For InSb spectra, the $0.9 \mathrm{~cm}^{-1}$ chan- 
neling generates amplitudes of $0.9 \%, 0.45 \%$ and $0.19 \%$ o for beam splitters with wedges of $0.5,1.27$ and $2.2^{\circ}$, respectively.

To ensure compatibility between different beam splitters, the wedge should be limited to $0.8^{\circ}$. This design will be implemented in future Bruker HR spectrometers. Figure 8 (lower panels) presents test spectra with an air gap wedge of 0.5 and $0.8^{\circ}$. In the 850 to $900 \mathrm{~cm}^{-1}$ spectral range, even the slightly increased wedge reduces the channeling by nearly $50 \%$ (from $10 \%$ to $6 \%$ ). In the 950 to $1000 \mathrm{~cm}^{-1}$ range, however, the effect is smaller. Although the same spectrometer and beam splitter were used in the right- and left-hand panels, the channeling amplitudes as well as the reduction factor vary. This is due to wavelength-dependent reflectivity of the beam splitter.

Moreover, this exercise demonstrates that a wedge of about $2^{\circ}$ on the air gap eliminates channeling even without a larger wedge of the beam splitter substrate. However, such a spectrometer completely free of channeling would result in non-interchangeability with beam splitters having a smaller air gap wedge and therefore the need to realign the spectrometer after a beam splitter exchange. Furthermore, when switching from small to large wedges, two new matched beam splitters are needed since the $\mathrm{KBr}$ beam splitter does not transmit visible light, and therefore a second one (normally $\mathrm{CaF}_{2}$ or glass) is needed for the alignment procedure. Switching within this new pair of beam splitters is possible without realignment. The ILS of the spectrometers with such a pair of beam splitters is good.

\section{Conclusions}

Firstly, this paper documents the channeling amplitudes for nearly all of the FTIR spectrometers used in NDACC. Such a systematic performance analysis is needed for improving the trace gas retrievals and for calculating complete error budgets and also to improve the consistency and quality of the products across the NDACC network.

Within NDACC, laboratory test spectra of about $20 \mathrm{spec}-$ trometers were recorded and analyzed. The derived channeling amplitudes range from $0.1 \%$ to $2.0 \%$ and from $0.3 \%$ to $21 \%$ in the $\mathrm{InSb}$ and $\mathrm{HgCdTe}$ domains, respectively. These values are not negligible when constructing the error budget of minor trace gases. A reduction of the channeling amplitudes is highly desirable for the analysis of gases like $\mathrm{ClONO}_{2}, \mathrm{HNO}_{3}, \mathrm{HCHO}$ and $\mathrm{SF}_{6}$ since these species typically absorb on the order of about $5 \%\left(\mathrm{ClONO}_{2}, \mathrm{HCHO}\right)$ to $50 \%$ o $\left(\mathrm{HNO}_{3}\right)$ of the incoming infrared light in the center of the signature.

Secondly, this study shows the potential to reduce channeling in several spectrometers and to improve the homogeneity within the network. The channeling frequencies allow us to determine the responsible optical component. A few instruments show channeling with a frequency of a few wavenum- bers due to insufficiently wedged detector windows. Switching the detector window or, more easily, the entire detector including the dewar and detector window will help reduce channeling in these cases.

Finally, we found that most spectrometers show two dominant channeling frequencies with about 0.1 or 0.2 and $0.9 \mathrm{~cm}^{-1}$ corresponding to the beam splitter substrate and beam splitter air gap, respectively, with the latter usually being dominant. The option of reducing this channeling contribution was investigated by adjusting the wedge angles on a test beam splitter. Increasing the wedge of this gap significantly reduces the channeling at $0.9 \mathrm{~cm}^{-1}$, and therefore such a beam splitter design offers the promise of further reducing channeling. As a result of this study, Bruker changed the standard air gap wedge of its beam splitters from 0.5 to $0.8^{\circ}$. Furthermore, beam splitters with a wedge of $2^{\circ}$ are available on request. Switching to this modified beam splitter design would contribute to further homogenization of the spectrometers operated within NDACC. 


\section{Appendix A}

Table A1. List of optical filters used in the IRWG (InfraRed Working Group) of NDACC.

\begin{tabular}{lrrl}
\hline Filter number & Spectral range $[\mu \mathrm{m}]$ & Spectral range $\left[\mathrm{cm}^{-1}\right]$ & Target species examples \\
\hline 1 & $2.2-2.6$ & $3850-4550$ & $\mathrm{HF}$ \\
2 & $2.6-3.3$ & $3030-3850$ & $\mathrm{HCN}$ \\
3 & $3.2-4.1$ & $2440-3130$ & $\mathrm{HCl}, \mathrm{CH}_{4}, \mathrm{C}_{2} \mathrm{H}_{6}, \mathrm{HCHO}, \mathrm{NO}_{2}$ \\
4 & $3.9-5.0$ & $2000-2560$ & $\mathrm{~N}_{2} \mathrm{O}$ \\
5 & $4.6-6.3$ & $1590-2170$ & $\mathrm{CO}, \mathrm{NO}, \mathrm{OCS}$ \\
6 & $>7.4$ & $<1350$ & $\mathrm{O}_{3}, \mathrm{ClONO}_{2}, \mathrm{HNO}_{3}, \mathrm{SF}_{6}$ \\
7 & $9.8-13.0$ & $770-1020$ & $\mathrm{O}_{3}, \mathrm{ClONO}_{2}, \mathrm{HNO}_{3}$ \\
8 & $7.5-10.2$ & $980-1330$ & $\mathrm{O}_{3}$ \\
\hline
\end{tabular}

\section{Appendix B: Source code for predicting fringe amplitudes generated by a wedged plate}

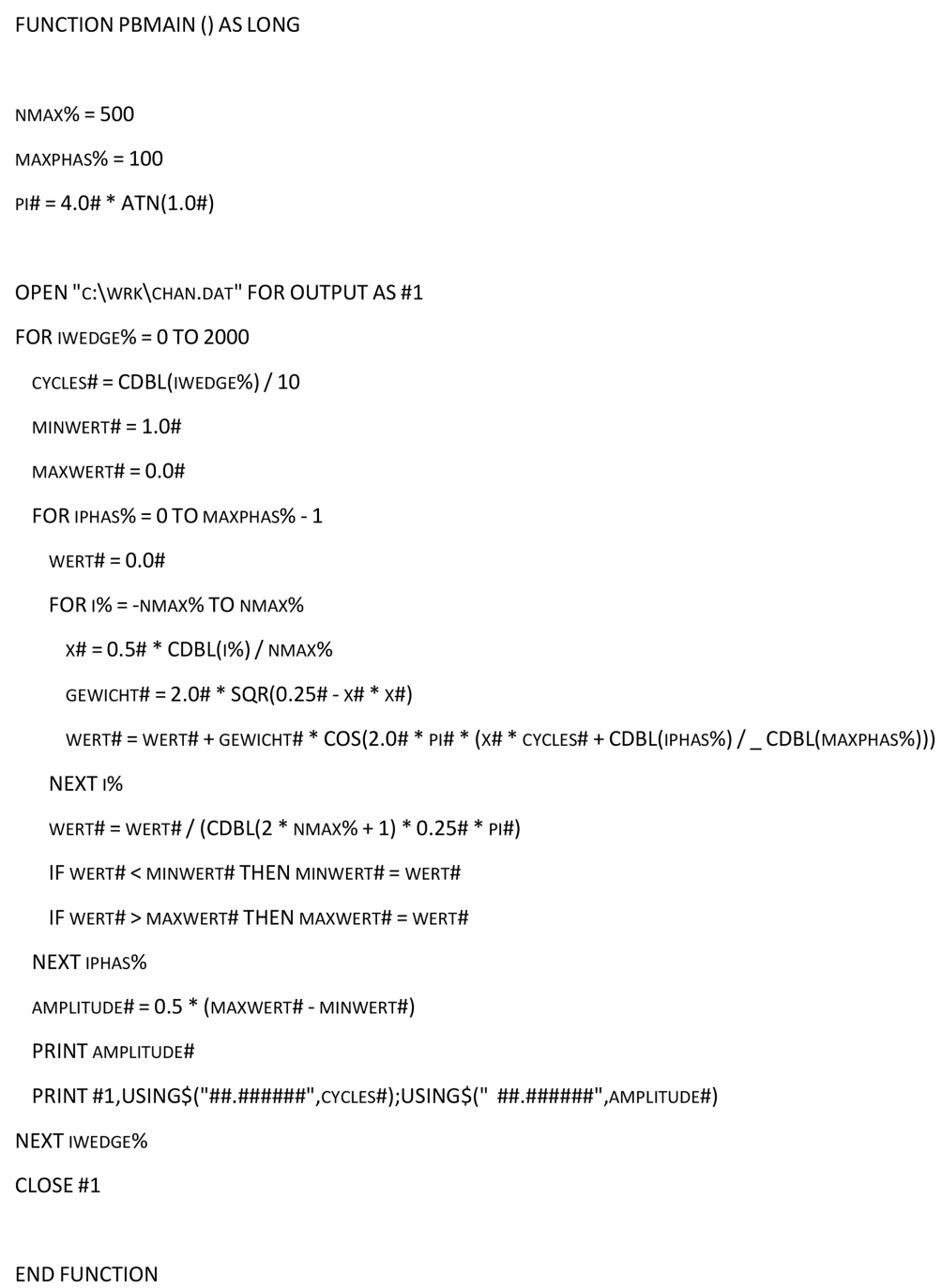


Code availability. The results of this paper are calculated with commercial software Origin ${ }^{\mathrm{TM}}$ and OPUS ${ }^{\mathrm{TM}}$, a software package from Bruker Optics, as described in Sect. 3.2. For the calculation of the fringing amplitudes which underlies Fig. 2, a short BASIC code has been created by Frank Hase (see Appendix A2). It is written in BASIC and is intended for compilation using the PowerBASIC console compiler.

Data availability. Channeling test spectra used in this study are available on request from the corresponding author (thomas.blumenstock@kit.edu).

Author contributions. TB designed the study, performed the analysis and wrote the paper. FH designed the analysis of the test spectra and wrote Sect. 2 of the paper. AK improved the beam splitter and provided test spectra. All other authors did lab measurements and provided test spectra. All authors read and provided feedback on the paper.

Competing interests. The authors declare no competing interests.

Acknowledgements. We acknowledge Gerhard Kopp for stimulating discussions on Fabry-Pérot fringing effects. The authors from the U Liège team acknowledge that the International Foundation High Altitude Research Stations Jungfraujoch and Gornergrat (HFSJG), 3012 Bern, Switzerland, made it possible to carry out our experiment at the Jungfraujoch station. We would like to thank AWI Bremerhaven and the personnel at the AWIPEV station, NyÅlesund (Spitsbergen), for logistic and on-site support.

Financial support. Part of this work was supported by Ministerio de Economía y Competitividad from Spain (project INMENSE no. CGL2016-80688-P). The Altzomoni site UNAM (DGAPA (grant nos. IN111418 and IN107417)) was supported by the CONACYT (grant no. 290589) and PASPA. The Paris site has received funding from Sorbonne Université, the French research center (CNRS) and the French space agency (CNES). Operations at the Rikubetsu and Tsukuba sites are supported in part by the GOSAT series project. The SPbU team was supported by Russian Foundation for Basic Research (project no. 18-05-00011). The Lauder and Arrival Heights FTIR measurements are core funded by NIWA through New Zealand's Ministry of Business, Innovation and Employment Strategic Science Investment Fund. Antarctica New Zealand supported the FTIR measurements at Arrival Heights, which includes test spectra collection. The Jungfraujoch FTIR experiment has received funding from the FRS - FNRS, Fédération Wallonie-Bruxelles, both in Brussels, Belgium, and from the GAW-CH program of MeteoSwiss. Eureka measurements were made at the Polar Environment Atmospheric Research Laboratory (PEARL), primarily supported by the Natural Sciences and Engineering Research Council of Canada (NSERC), Environment and Climate Change Canada, and the Canadian Space Agency. Toronto measurements were made at the University of Toronto Atmospheric Observatory (TAO), primarily supported by NSERC and the Uni- versity of Toronto. The National Center for Atmospheric Research is sponsored by the National Science Foundation. The NCAR FTS observation programs at Thule, GR, Mauna Loa, HI, and Boulder, $\mathrm{CO}$, are supported under contract by the National Aeronautics and Space Administration (NASA). The Bremen, Garmisch, Izaña, Karlsruhe and Ny-Ålesund FTIR stations have been supported by the German Bundesministerium für Wirtschaft und Energie (BMWi) via DLR (grant nos. 50EE1711A-B and D). This work has been supported by the Federal Ministry of Education and Research (BMBF) Germany in the project TroStra (grant no. 01LG1904A).

The article processing charges for this open-access publication were covered by a Research Centre of the Helmholtz Association.

Review statement. This paper was edited by Saulius Nevas and reviewed by Arndt Meier and two anonymous referees.

\section{References}

Abrams, M. C., Toon, G. C., and Schindler, R. A.: Practical example of the correction of Fourier-transform spectra for detector nonlinearity, Appl. Optics, 33, 6307-6314, https://doi.org/10.1364/AO.33.006307, 1994.

De Mazière, M., Thompson, A. M., Kurylo, M. J., Wild, J. D., Bernhard, G., Blumenstock, T., Braathen, G. O., Hannigan, J. W., Lambert, J.-C., Leblanc, T., McGee, T. J., Nedoluha, G., Petropavlovskikh, I., Seckmeyer, G., Simon, P. C., Steinbrecht, W., and Strahan, S. E.: The Network for the Detection of Atmospheric Composition Change (NDACC): history, status and perspectives, Atmos. Chem. Phys., 18, 4935-4964, https://doi.org/10.5194/acp-18-4935-2018, 2018.

Dohe, S., Sherlock, V., Hase, F., Gisi, M., Robinson, J., Sepúlveda, E., Schneider, M., and Blumenstock, T.: A method to correct sampling ghosts in historic near-infrared Fourier transform spectrometer (FTS) measurements, Atmos. Meas. Tech., 6, 1981-1992, https://doi.org/10.5194/amt-6-1981-2013, 2013.

Gisi, M., Hase, F., Dohe, S., and Blumenstock, T.: Camtracker: a new camera controlled high precision solar tracker system for FTIR-spectrometers, Atmos. Meas. Tech., 4, 47-54, https://doi.org/10.5194/amt-4-47-2011, 2011.

Hase, F., Blumenstock, T., and Paton-Walsh, C.: Analysis of the instrumental line shape of high-resolution Fourier transform IR spectrometers with gas cell measurements and new retrieval software, Appl. Optics, 38, 3417-3422, 1999.

Hase, F., Hannigan, J. W., Coffey, M. T., Goldman, A., Höpfner, M., Jones, N. B., Rinsland, C. P., and Wood, S. W.: Intercomparison of retrieval codes used for the analysis of high-resolution, ground-based FTIR measurements, J. Quant. Spectrosc. Ra., 87, 25-52, 2004.

Hecht, E.: Optics,Pearson Education, 5th edn., Harlow, ESSEX, UK, ISBN 978013397726, 440 pp., 2017.

Ismail, N., Calil Kores, C., Geskus, D., and Pollnau, M.: The Fabry-Pérot resonator: Spectral line shapes, generic and related Airy distributions,linewidths, finesses, and performance at low or frequency-dependent reflectivity, Opt. Express, 24, 1636616389, https://doi.org/10.1364/OE.24.016366, 2016. 
Keppel-Aleks, G., Toon, G. C., Wennberg, P. O., and Deutscher, N. M.: Reducing the impact of source brightness fluctuations on spectra obtained by Fourier-transform spectrometry. Appl. Optics, 46, 4774-4779, PMID 17609726 https://doi.org/10.1364/AO.46.004774, 2007.

Messerschmidt, J., Macatangay, R., Notholt, J., Petri, C., Warneke,T., and Weinzierl, C.: Side by side measurements of $\mathrm{CO}_{2}$ by ground-based Fourier transform spectrometry (FTS), Tellus B, 62, 749-758, https://doi.org/10.1111/j.16000889.2010.00491.x, 2010.

Schneider, M. and Hase, F.: Technical Note: Recipe for monitoring of total ozone with a precision of around 1 DU applying midinfrared solar absorption spectra, Atmos. Chem. Phys., 8, 63-71, https://doi.org/10.5194/acp-8-63-2008, 2008.

Vigouroux, C., Bauer Aquino, C. A., Bauwens, M., Becker, C., Blumenstock, T., De Mazière, M., García, O., Grutter, M., Guarin, C., Hannigan, J., Hase, F., Jones, N., Kivi, R., Koshelev, D., Langerock, B., Lutsch, E., Makarova, M., Metzger, J.-M., Müller, J.-F., Notholt, J., Ortega, I., Palm, M., Paton-Walsh, C., Poberovskii, A., Rettinger, M., Robinson, J., Smale, D., Stavrakou, T., Stremme, W., Strong, K., Sussmann, R., Té, Y., and Toon, G.: NDACC harmonized formaldehyde time series from 21 FTIR stations covering a wide range of column abundances, Atmos. Meas. Tech., 11, 5049-5073, https://doi.org/10.5194/amt-11-5049-2018, 2018.
Vigouroux, C., Langerock, B., Bauer Aquino, C. A., Blumenstock, T., Cheng, Z., De Mazière, M., De Smedt, I., Grutter, M., Hannigan, J. W., Jones, N., Kivi, R., Loyola, D., Lutsch, E., Mahieu, E., Makarova, M., Metzger, J.-M., Morino, I., Murata, I., Nagahama, T., Notholt, J., Ortega, I., Palm, M., Pinardi, G., Röhling, A., Smale, D., Stremme, W., Strong, K., Sussmann, R., Té, Y., van Roozendael, M., Wang, P., and Winkler, H.: TROPOMI-Sentinel-5 Precursor formaldehyde validation using an extensive network of ground-based Fouriertransform infrared stations, Atmos. Meas. Tech., 13, 3751-3767, https://doi.org/10.5194/amt-13-3751-2020, 2020.

Wikipedia.org: Fabry-Pérot interferometer, available at: https:// en.wikipedia.org/wiki/Fabry-Perot_interferometer, last access: 2 February 2021.

Wunch, D., Toon, G. C., Wennberg, P. O., Wofsy, S. C., Stephens, B. B., Fischer, M. L., Uchino, O., Abshire, J. B., Bernath, P., Biraud, S. C., Blavier, J.-F. L., Boone, C., Bowman, K. P., Browell, E. V., Campos, T., Connor, B. J., Daube, B. C., Deutscher, N. M., Diao, M., Elkins, J. W., Gerbig, C., Gottlieb, E., Griffith, D. W. T., Hurst, D. F., Jiménez, R., Keppel-Aleks, G., Kort, E. A., Macatangay, R., Machida, T., Matsueda, H., Moore, F., Morino, I., Park, S., Robinson, J., Roehl, C. M., Sawa, Y., Sherlock, V., Sweeney, C., Tanaka, T., and Zondlo, M. A.: Calibration of the Total Carbon Column Observing Network using aircraft profile data, Atmos. Meas. Tech., 3, 1351-1362, https://doi.org/10.5194/amt-3-1351-2010, 2010. 